\title{
Experimental Study on Thermal Pyrolysis of Biomass in Molten Salt Media
}

\author{
Hongtao JiAng, Ning AI,* Min Wang, Dengxiang Ji, and Jianbing Ji* \\ College of Chemical Engineering and Materials Science, Zhejiang University of Technology (Hangzhou 310014; \\ China)
}

Received April 27, 2009 ; Accepted June 19, 2009

\begin{abstract}
Pyrolysis of biomass in molten salt media have been conducted in a stainless steel reactor. Five kinds of mixed molten salts were used as thermal pyrolysis media and six kinds of biomass as feedstock. The experiments were carried out under atmospheric pressure and $400-600^{\circ} \mathrm{C}$. The pyrolysis oils were examined using some spectroscopic and chromatographic analysis techniques. The effects of the type of molten salts and feeding conditions, reaction conditions, including temperature and space velocity, on yield of liquid product were investigated. This paper reports the feasibility for producing bio-fuels and bio-chemicals through the pyrolysis of biomass in molten salt media.
\end{abstract}

Key Words : Biomass, Bio-oil, Pyrolysis, Molten Salt

\section{Introduction}

With the depletion of fossil fuel and the concern of environmental protection, the utilization of biomass energy has received much attention. The biomass can be turned into useful energy product by e.g. thermochemical conversion processes. Bio-oil, which is liquid product acquired from biomass by thermochemical conversion method, may be used to substitute power fuel, to gain hydrogen by catalytic reforming and to extract chemical products including food flavoring, chemical, fertilizer, etc. Moreover, it does not contribute a net rise in the level of $\mathrm{CO}_{2}$ in the atmosphere, and consequently to the greenhouse effect. Therefore, bio-oil could be recognized as a potential source of renewable energy based on both benefits of energy recovery and environmental protection. Bio-oil is a focal point of research in the cleaning utilization technology of biomass energy.

Pyrolysis, one of biomass thermochemical conversion methods, is generally described as the thermal decomposition of the organic components in biomass waste in the absence of oxygen at mediate temperature, to yield tar (pyrolysis oil), char (charcoal) and gaseous fractions (fuel gases). For convenience, there are two approaches for the bio-oil production technology. One, called as flash or fast pyrolysis, is to maximize the yield of liquid product at the processing conditions of (1) very high heating rate (about $1000 \mathrm{~K} / \mathrm{s}$ ) and heat transfer rate, (2) moderate reaction temperature (around $500{ }^{\circ} \mathrm{C}$ ), and (3) rapid cooling of the pyrolysis vapors to give the bio-crude products. Another, called as high-pressure liquefaction, is to maximize the yield of liquid product at the processing conditions of (1) the temperature between 200 and $400{ }^{\circ} \mathrm{C}$, (2) the pressure between 5 and $25 \mathrm{MPa}$, (3) the reaction time between 2 minutes to several hours, (4) in presence of solvent. During the last thirty years, a large amount of research on those two biomass pyrolysis technologies has been carried out and various biomass materials were used, such as sunflower (Gercel, 2002), ${ }^{1)}$ rapeseed (Sensoz et al., 2000), ${ }^{2)}$ cotton stalk (Putun, 2002), ${ }^{3)}$ linseed (Acikgoz et al., 2004), ${ }^{4)}$ micro-algae (Xiaoling et al., 2004), ,) rice stalk (Luo et al., 2004), ${ }^{6}$ corn stalk (Bai et al., 2005), ${ }^{7)}$ esparto (Debdoubi et al., 2006), ${ }^{8)}$ elm sawdust (Liu et al., 2008), ${ }^{9)}$ safflower seed (Sensoz et al., 2008), ${ }^{10}$ and oak trees sawdust (Park et al., 2009). ${ }^{11}$ ) These studies showed that the parameters such as temperature, particle size, heating rate, and residence time have an effect on the products yields of pyrolysis. However, the bio-oil was found to be highly oxygenated, complex, and chemically unstable. Industrialized production technology of biomass pyrolysis has not been formed.

Molten salt consists of alkali metal salt and alkaline earth salt (i.e., halides, silicates, carbonates and phosphates). It is ionic crystals under solid state and will melt into ionic liquid at high temperature. Molten salts combines advantages of good electrical conductivity, broad service range of temperature, good thermal stability, low vapour pressure, large heat capacity, large thermal conductivity, good dissolution ability and low viscosity, as well as good chemical stability.

Molten salt is wildly used in the field of petroleum refining, high-temperature electrocatalysis, hot corrosion and electrochemical antiseptic. Good results were also gained in the pyrolysis process of waste rubber and electronic waste. Pyrolysis process of two kinds of lignins were studied (Sada et al., 1992) ${ }^{12)}$ using mixtures of molten $\mathrm{ZnCl}_{2}$ and $\mathrm{KCl}$ with molar ratios of $3 / 7$ and $7 / 6$, and the yield of phenolic compounds were measured. Pyrolysis of kraft lignin was carried out (Kudsy et al., 1999) ${ }^{13)}$ using mixtures of molten $\mathrm{ZnCl}_{2}$ and $\mathrm{KCl}$ at three levels of temperature, $500{ }^{\circ} \mathrm{C}, 550{ }^{\circ} \mathrm{C}$ and $600{ }^{\circ} \mathrm{C}$, and three levels of salt-to-lignin ratio, 1,2 and 3 . Nineteen kinds of phenolic compound were identified and their quantitative determinations were made by gas chromatography. But further researches on biomass pyrolysis in molten salt media have been seldom reported.

In this paper, pyrolysis of biomass in molten salt media 
to produce bio-oil was carried out in a self-designed reactor. The effects of the composition of molten salt, feeding conditions, and reaction conditions on yield of liquid product and chemical compositions of bio-oil were investigated by means of experimental studies, elemental analysis, IR and GC-MS.

\section{1 Biomass Materials}

\section{Experimental}

Agricultural and forestry wasters, including fir sawdust, birch sawdust, redwood sawdust, rice stalk, cole stalk and rice husk were used as biomass materials in this paper. The birch sawdust was from Northeast China and other biomass materials were from East China.

The chemical quantitative analysis method improved on the basis of X.H. method was established in our previous study. Specifically, the cellulose content was determined by acid-hydrolysis method, the hemicellulose content was determined by colorimetric method, and the lignin content was determined by $72 \%$ sulfuric acid method.

Three trace metal elements (potassium, calcium and iron) were determined by ICP-MS method after $\mathrm{H}_{2} \mathrm{SO}_{4}$ $\mathrm{H}_{2} \mathrm{O}_{2}$ digestion.

\section{2 Molten salts}

Zinc chloride, potassium chloride, potassium nitrate, sodium nitrate $\left(\mathrm{NaNO}_{3}\right.$ and $\mathrm{NaNO}_{2}$ ), cuprous chloride and other reagents are from SINOPHARM Chemical Reagent Co., Ltd with purity of more than $99.0 \%$.

Thermal analysis method was employed to measure the melting points of mixed molten salts. Samples were heated to melt into homogeneous solution and then cooling gradually in a constant-temperature environment. The cooling rate was set between 2 to $4{ }^{\circ} \mathrm{C}$ per minute. The temperature was recorded every 20 second, until the temperature is $50^{\circ} \mathrm{C}$ lower than three-phase coexistence temperature.

\section{3 Pyrolysis}

2. 3. 1 Samples and Sample Preparation The biomass sample was sieved and the fraction saved for the pyrolysis experiments was $60-100$ mesh. The biomass sample was dried at $105^{\circ} \mathrm{C}$ prior to the experiments.

\section{3. 2 Equipment The pyrolysis reactor}

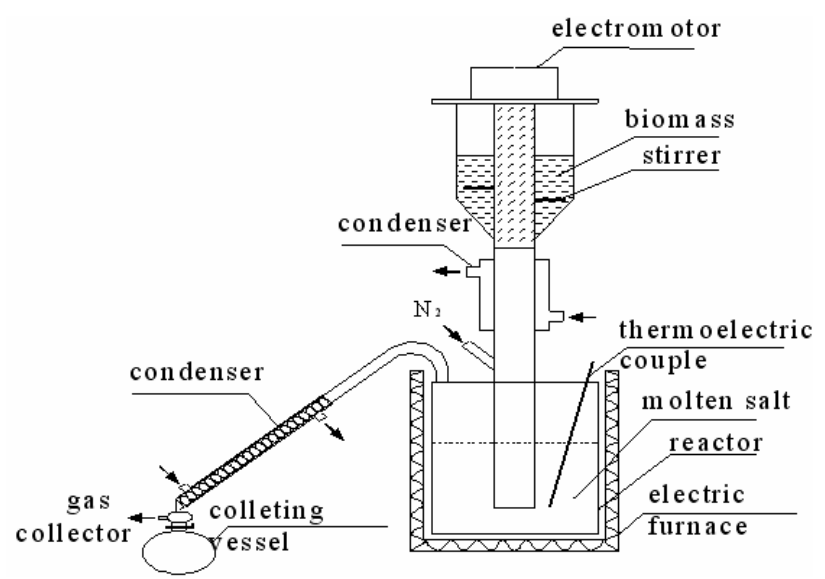

Fig. 1 Schematic diagram of experimental apparatus. consisted of a reactor, a biomass screw feeder, a set of heater and a set of cooler, as illustrated in Fig. 1. The stainless steel reactor had an inner diameter of $95 \mathrm{~mm}$ and a height of $150 \mathrm{~mm}$, equipped with feed inlet, gas outlet, and thermocouple tube. The heating furnace with a programmed temperature controller was speciallydesigned by Hangzhou LANTIAN Co., Ltd. The temperature was monitored and controlled by K-type thermocouples inside the thermocouple tube. A variablespeed DC motor was employed adjusted the rotational speed of the screw feeder. The gas flow was divided so that one third went through the bottom of the reactor and the remaining two thirds through the feeder. At the end of feed tube, a cooling jacket was equipped to prevent coking as the biomass sample meet the molten salt soon. The liquid products (bio-oil + water) were collected by condensing in cold traps maintained at about $0^{\circ} \mathrm{C}$. The cooler system was made of quartz, in favor of observing condensation condition.

2. 3. 3 Procedure Preliminary, molten salt $(\sim 700$ g) were put into reactor. When the heating was started, nitrogen gas continuously flowed into the reactor to guarantee an 'oxygen-free' environment. As soon as the reactor temperature reached the reaction temperature, the circulating cooling water system began to work and the pre-treated biomass sample was injected into the reactor through feeding system. The biomass underwent a flash pyrolysis and was converted into volatiles which were mainly condensed into the recuperation system as a bio-oil. At the end of the experiments, the liquid product (bio-oil and water) was weighed. The residues in reactor were dissolved by water then the solid was dried and weighed to determine char yield. The gas yield was calculated from the material balance.

2. 3. 4 Characterization The FT-IR spectra of the bio-oil was recorded by using a Nicolet 6700 Fourier transform infrared (FTIR) spectrophotometer. The measurements are conducted between 4000 and $650 \mathrm{~cm}^{-1}$.

Chemical class composition of the bio-oils was analyzed by GC/MS. A gas chromatograph, equipped with a DB17MS $(30 \mathrm{~m} \times 0.25 \mathrm{~mm} \times 0.25 \mu \mathrm{m})$ capillary column, was used for compound separation. The injector and detector temperatures were both at $270^{\circ} \mathrm{C}$. Helium was used as carried gas with a constant flow of $1 \mathrm{~mL} / \mathrm{min}$. Oven program was as follows: hold constant at $50^{\circ} \mathrm{C}$ for $4 \mathrm{~min}$ then heat with $8{ }^{\circ} \mathrm{C} / \mathrm{min}$ to $250^{\circ} \mathrm{C}$ and hold for $10 \mathrm{~min}$. Mass spectra were recorded under electron impact (70 $\mathrm{eV})$ at a frequency of $1 \mathrm{scan} \mathrm{s} \mathrm{s}^{-1}$ over a $\mathrm{m} / \mathrm{z}$ range of 45 450.

\section{Results and Discussion}

\section{1 Component analysis of biomass material}

\section{1. 1 Contents of cellulose, hemicellulose and lignin}

The contents of cellulose, hemicellulose and lignin in those six kinds of biomass were measured as listed in Table 1.

The total contents of cellulose, hemicellulose and lignin in six kinds of biomass are about $80 \%$. The cellulose contents in sawdust and rice husk are higher than that in rice stalk or cole stalk. 
3. 1. 2 Metal contents Three trace metal elements (potassium, calcium and iron) were determined by ICP-MS method after $\mathrm{H}_{2} \mathrm{SO}_{4}-\mathrm{H}_{2} \mathrm{O}_{2}$ digestion as listed in Table 2.

The content of potassium ion in agricultural wasters (rice stalk, cole stalk and rice husk) was significantly higher than that in forestry wasters (fir sawdust, birch sawdust and redwood sawdust). The contents of potassium and calcium ions in rice stalk were higher than those in other biomass materials.

\section{2 Melting points of mixed molten salts}

Reaction temperature, is one of the main influence factors in biomass pyrolysis process..$^{7-11)}$ It is generally believed that $450{ }^{\circ} \mathrm{C}$ to $600{ }^{\circ} \mathrm{C}$ is the appropriate reaction temperature. In order to heat the biomass particles achieving the reaction temperature with an appropriate rate, the melting point of molten salt should be below $300{ }^{\circ} \mathrm{C}$ The melting point of molten salts used in this paper was given in Table 3.

\section{3 Pyrolysis results}

3. 3. 1 Effect of inert gases Inert gas served to provide oxygen free environment, to accelerate mixing of molten salts and biomass particles, and to bring pyrolysis gas out of reactor to prevent secondary cracking reactions of the primary pyrolysis gases.

The effects of inert gas on bio-oil yield and water con-

Table 1 Contents of cellulose, hemicellulose and lignin in biomass.

\begin{tabular}{ccccc}
\hline Biomass type & $\begin{array}{c}\text { Cellulose } \\
\text { (wt.\%) }\end{array}$ & $\begin{array}{c}\text { Hemicellulose } \\
\text { (wt.\%) }\end{array}$ & $\begin{array}{c}\text { Lignin } \\
\text { (wt.\%) }\end{array}$ & $\begin{array}{c}\text { Total } \\
\text { (wt.\%) }\end{array}$ \\
\hline Fir sawdust & 48.6 & 6.5 & 22.3 & 77.4 \\
Birch sawdust & 41.7 & 28.5 & 16.9 & 87.1 \\
Redwood sawdust & 33.6 & 6.0 & 35.7 & 75.3 \\
Rice husk & 45.6 & 13.5 & 22.4 & 81.5 \\
Rice stalk & 31.7 & 19.0 & 21.5 & 72.2 \\
Cole stalk & 28.1 & 9.0 & 30.3 & 67.4 \\
\hline
\end{tabular}

Table 2 Contents of metal ions in biomass material.

\begin{tabular}{cccc}
\hline \multirow{2}{*}{ Biomass type } & \multicolumn{3}{c}{ The content of metal ions $(\mu \mathrm{g} / \mathrm{g})$} \\
\cline { 2 - 4 } & Potassium & Calcium & Iron \\
\hline Fir sawdust & 714 & 538 & 230 \\
Birch sawdust & 570 & 265 & 31.9 \\
Redwood sawdust & 797 & 1268 & $-^{*}$ \\
Rice husk & 1247 & - & 80.8 \\
Rice stalk & 10148 & 2496 & 297 \\
Cole stalk & 1289 & 347 & 593 \\
\hline
\end{tabular}

* Not detected

Table 3 Melting point of molten salts.

\begin{tabular}{cc}
\hline Molten salts composition $(\mathrm{mol} \%)$ & Melting point $\left({ }^{\circ} \mathrm{C}\right)$ \\
\hline $\mathrm{ZnCl}_{2}$ & 280 \\
$53.8 \mathrm{ZnCl}_{2}-\mathrm{KCl}$ & 181 \\
$48.1 \mathrm{ZnCl}_{2}-41.1 \mathrm{KCl}-\mathrm{CuCl}$ & 190 \\
$65.6 \mathrm{KCl}-\mathrm{CuCl}$ & 220 \\
$53.1 \mathrm{KNO}_{3}-40.1 \mathrm{NaNO}_{2}-\mathrm{NaNO}_{3}$ & 142 \\
\hline
\end{tabular}

tent of bio-oil were investigated. Two kinds of inert gas, $\mathrm{N}_{2}$ and $\mathrm{CO}_{2}$, were examined. The flow rate of inert gas was varied from $100 \mathrm{~L} / \mathrm{h}$ to $400 \mathrm{~L} / \mathrm{h}$. The results show that inert gas flow rate has little influences on bio-oil yields and water contents.

3. 3. 2 Effect of temperature Temperature is a key factor for biomass pyrolysis. As shown in Fig. 2, The effects of pyrolysis temperature on yields of bio-oil, char and gas from cellulose pyrolysis in $\mathrm{ZnCl}_{2}-\mathrm{KCl}$ were examined under atmospheric pressure with $\mathrm{N}_{2}$ flow rate of $200 \mathrm{~L} / \mathrm{h}$.

From Fig. 2, the yield of char, bio-oil and gas product from cellulose pyrolysis at $410{ }^{\circ} \mathrm{C}$ were $38 \%, 48 \%$, and $14 \%$ respectively. Increasing temperatures have been associated with not only primary pyrolysis of biomass to increase bio-oil yield but also secondary cracking reactions of the pyrolysis gases to increase the gas yields and to reduce the bio-oil yield.,10) Water content of bio-oil decreased from $78 \%$ to $37 \%$ with increasing temperature from $410{ }^{\circ} \mathrm{C}$ to $520{ }^{\circ} \mathrm{C}$, indicating depolymerization of cellulose to produce bio-oil was predominate reaction at higher pyrolysis temperature. Similar to the other methods of biomass pyrolysis, ${ }^{9,11}$ the yields of bio-oil product from biomass pyrolysis in molten salts increased and then decreased with increasing pyrolysis temperature. For cellulose feed, the optimal pyrolysis temperature was about $530{ }^{\circ} \mathrm{C}$.

\section{3. 3 Effect of molten salts Table 4 shows the} effect of molten salts composition on liquid product from cellulose. $\mathrm{ZnCl}_{2}$ made the yield of bio-oil product reach maximum. It was attributed to the catalytic effects of $\mathrm{ZnCl}_{2}$ on biomass pyrolysis. In order to adjust the functionality of $\mathrm{ZnCl}_{2}$, the other salts were added. The yield of bio-oil product from biomass pyrolysis in $\mathrm{KNO}_{3}$ $\mathrm{NaNO}_{2}-\mathrm{NaNO}_{3}$ was zero, indicating nitrates were not suitable for biomass pyrolysis. The yield and the water content of bio-oil from biomass pyrolysis in $\mathrm{ZnCl}_{2}-\mathrm{KCl}$ were $1.6 \%$ and $50 \%$ respectively. Adding $\mathrm{CuCl}$ (reducing additive) to $\mathrm{ZnCl}_{2}-\mathrm{KCl}$ decreased water content from $46 \%$ to $21 \%$, whereas it did not change the yield of

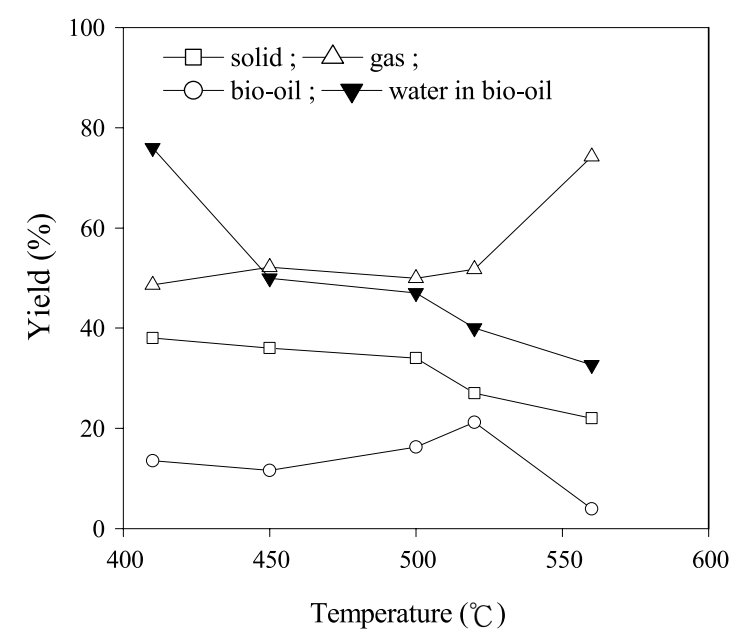

Fig. 2 Effect of pyrolysis temperature on the yield of pyrolysis product. 
Table 4 Effect of molten salts composition on liquid product from cellulose.

\begin{tabular}{cccc} 
& $\left(450^{\circ} \mathrm{C}, \mathrm{N}_{2}\right.$ flow rate $\left.=200 \mathrm{~L} / \mathrm{h}\right)$ \\
\hline $\begin{array}{c}\text { Molten salts composition } \\
(\mathrm{mol} \%)\end{array}$ & $\begin{array}{c}\text { Yield of bio-oil } \\
(\%)\end{array}$ & $\begin{array}{c}\text { Water content in bio-oil } \\
(\%)\end{array}$ & $\begin{array}{c}\text { Yield of organic liquid } \\
(\%)\end{array}$ \\
\hline $\mathrm{ZnCl}_{2}$ & 35.0 & 46.0 & 18.9 \\
$53.8 \mathrm{ZnCl}_{2}-\mathrm{KCl}$ & 11.6 & 50.0 & 5.8 \\
$66 \mathrm{KCl}_{-} \mathrm{CuCl}$ & 11.8 & 21.0 & 9.3 \\
$49.2 \mathrm{ZnCl}_{2}-39.8 \mathrm{KCl}-\mathrm{CuCl}$ & 12.0 & 45.0 & 6.6 \\
$53 \mathrm{KNO}_{3}-40 \mathrm{NaNO}_{2}-\mathrm{NaNO}_{3}$ & 0 & 0 & 0 \\
$49.2 \mathrm{ZnCl}_{2}-42.2 \mathrm{KCl}_{-}-\mathrm{FeCl}_{2}$ & 15.0 & 44.0 & 8.4 \\
\hline
\end{tabular}

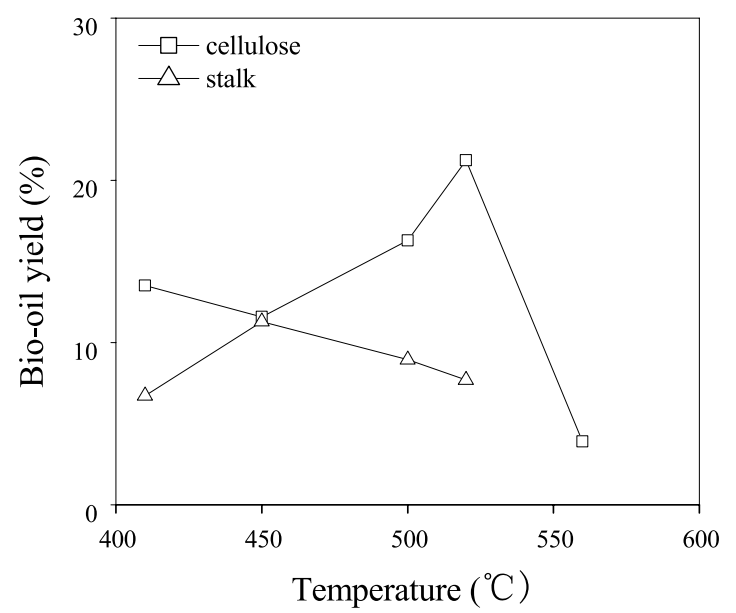

Fig. 3 Effect of pyrolysis temperature on the yield of biooil.

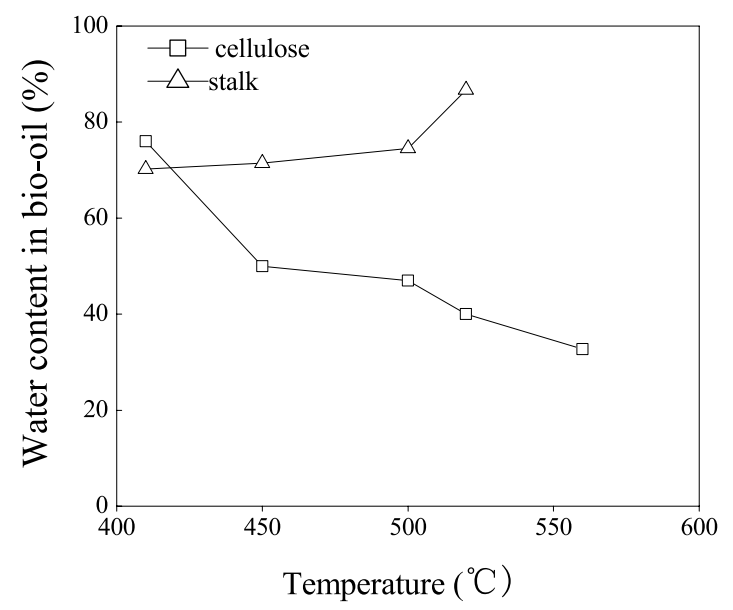

Fig. 4 Effect of pyrolysis temperature on the water content in bio-oil.

bio-oil product. $\mathrm{FeCl}_{2}$ displayed a similar effect on the process of biomass pyrolysis. Not only product yield, but also water content in bio-oil was influenced by composition of molten salts.

The effects of metal ions and of salts on products from pyrolysis of biomass have been reported. ${ }^{14-19)}$ The results of previous studies indicated that adding metal salts to pyrolysis system resulted in variation of yield and composition of pyrolysis oil. The yield of bio-oil product from biomass pyrolysis in molten salts was lower than that $(40-60 \%)$ from catalytic pyrolysis of biomass without

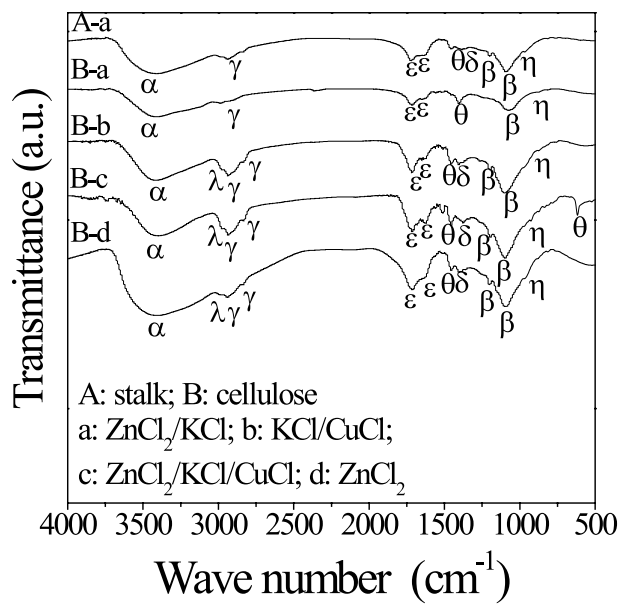

Fig. 5 IR spectrum of bio-oil

$\mathrm{O}-\mathrm{H}$ stretching vibrations $(\alpha)$; O-H in-plane deformations ( $\beta$ ) ; C-H stretching vibrations $(\gamma)$; $\mathrm{C}-\mathrm{H}$ deformation vibrations $(\delta) ; \mathrm{C}=\mathrm{O}$ stretching vibrations $(\varepsilon)$; C-O stretching vibrations $(\eta)$; hydrocarbon groups bound to aromatic rings $(\lambda)$; aromatic compounds $(\theta)$.

molten salts. ${ }^{12,16-18)}$ This phenomenon might result from the excessive pyrolysis of primary pyrolysis gas because of high viscosity of molten salts.

It has been found that zinc halides have a catalytic activity in coal depolymerization, ${ }^{20)}$ in ligin pyrolysis ${ }^{12)}$ and in cellulose pyrolysis. ${ }^{16)}$ However, it still keeps unclear on the reasons of catalytic performance of zinc halides. Further studies should be done to elucidate this phenomenon.

3. 3. 4 Effect of biomass materials Figures 3 and 4 show the yields and water content of the bio-oil products from pyrolysis of cellulose and rice stalk in $\mathrm{ZnCl}_{2}-\mathrm{KCl}\left(53.8 \mathrm{~mol} \% \mathrm{~mol}\right.$ of $\left.\mathrm{ZnCl}_{2}\right)$ at different temperatures. The yields of bio-oil product from both cellulose and rice stalk increased and then decreased with increasing temperature. Water content of bio-oil from rice stalk increased with increasing temperature. For rice stalk feeds, the optimal pyrolysis temperature $\left(450^{\circ} \mathrm{C}\right)$ was lower than that for cellulose. Product yield of the bio-oil from cellulose was higher than that from rice stalk. On contrast, water content of the bio-oil from cellulose was lower than that form rice stalk. These results indicated that cellulose was better than semicellulose and lignin for pyrolysis in molten salts. 
Table 5 Identification and yield (area \%) of liquid products.

\begin{tabular}{ccccc}
\hline Biomass & Peak No. & $\begin{array}{c}\text { Retention time } \\
(\mathrm{min})\end{array}$ & Name of compound & $\begin{array}{c}\text { Area } \\
(\%)\end{array}$ \\
\hline Cellulose & 1 & 4.30 & Furan, 2-methoxy- & 21.15 \\
& 2 & 20.3 & d-Gluconic acid, 2,3,4,6-tetra-O-methyl-, .delta-lactone & 12.04 \\
& 3 & 19.20 & 2,3-Di-O-methyl-D-xylopyranose & 10.96 \\
& 4 & 7.44 & Furan, 3-methyl- & 8.07 \\
& 5 & 18.90 & 1,5-Anhydro-2,3,4,6-tetra-O-methyl-D-mannitol & 7.40 \\
& 6 & 9.13 & Ethanone, 1-(2-furanyl)- & 6.24 \\
\hline Rice stalk & 1 & 7.94 & unidentified & 22.12 \\
& 2 & 7.7 & Furan, 3-methyl- & 11.85 \\
& 3 & 14.09 & unidentified & 11.46 \\
& 4 & 9.00 & unidentified & 10 \\
& 5 & 9.16 & 2-Cyclopenten-1-one, 3-methyl- & 6.81 \\
\hline
\end{tabular}

\section{3. 5 Analysis of bio-oil}

3. 3. 5. 1 IR spectra of bio-oil Functional group compositional analysis of bio-oil from cellulose and rice stalk obtained with various compositions of molten salts was determined by FT-IR spectrometry and results are shown in Fig. 5. The objective was to get the type of functional group of compounds in bio-oil, in order to establish the possible ways of reusing or treating and them. The FTIR spectra of the bio-oil samples obtained with different molten salts were similar. The $\mathrm{O}-\mathrm{H}$ stretching vibrations between 3300 and $3600 \mathrm{~cm}^{-1}$ indicate the presence of phenols and alcohols. The $\mathrm{C}=\mathrm{O}$ stretching vibrations with absorbance between 1680 and $1780 \mathrm{~cm}^{-1}$ represent the presence of ketones or aldehydes. C-O stretching vibrations between 850 and $950 \mathrm{~cm}^{-1}$ and $\mathrm{C}-\mathrm{O}$ stretching and $\mathrm{O}-\mathrm{H}$ in-plane deformations between 950 and $1325 \mathrm{~cm}^{-1}$ are sall present in bio-oil. The presence of both $\mathrm{O}-\mathrm{H}$ and $\mathrm{C}=\mathrm{O}$ stretching vibrations also indicates the presence of carboxylic acids and derivatives. Their presence in the bio-oil are representative of nonoxygenated compounds. The band at the about $3100 \mathrm{~cm}^{-1}$ may indicate the presence of hydrocarbon groups bound to aromatic rings. The $\mathrm{C}-\mathrm{H}$ stretching vibrations between 2800 and $3000 \mathrm{~cm}^{-1}$ and C$\mathrm{H}$ deformation vibrations between 1350 and $1450 \mathrm{~cm}^{-1}$ indicate the presence of alkanes. It seems likely that band overlapping occurs in this region because skeleton vibrations in aromatic rings also produce absorption between 1500 and $1450 \mathrm{~cm}^{-1}$. The adsorption peaks between 600 and $750 \mathrm{~cm}^{-1}$ and $1575-1625 \mathrm{~cm}^{-1}$ are characteristics of single ring aromatic compounds and polycyclic aromatic compounds.

3. 3. 5. $2 \mathrm{GC} / \mathrm{MS}$ analysis of bio-oil GC/MS analyses were carried out to identify the organic compounds in bio-oil. Figures 6 and 7 show the GC/MS chromatogram of bio-oil from cellulose and rice stalk obtained with $\mathrm{ZnCl}_{2}-\mathrm{KCl}$. Table 5 indicates the tentative compounds assigned for every identified peak. The biooil is a complicated organic compound. The application of different kinds of molten salts influenced the composition and the yield of organic compounds. The furan derivatives were absolutely dominant in content. Bio-oil from cellulose contained notable content of glucose

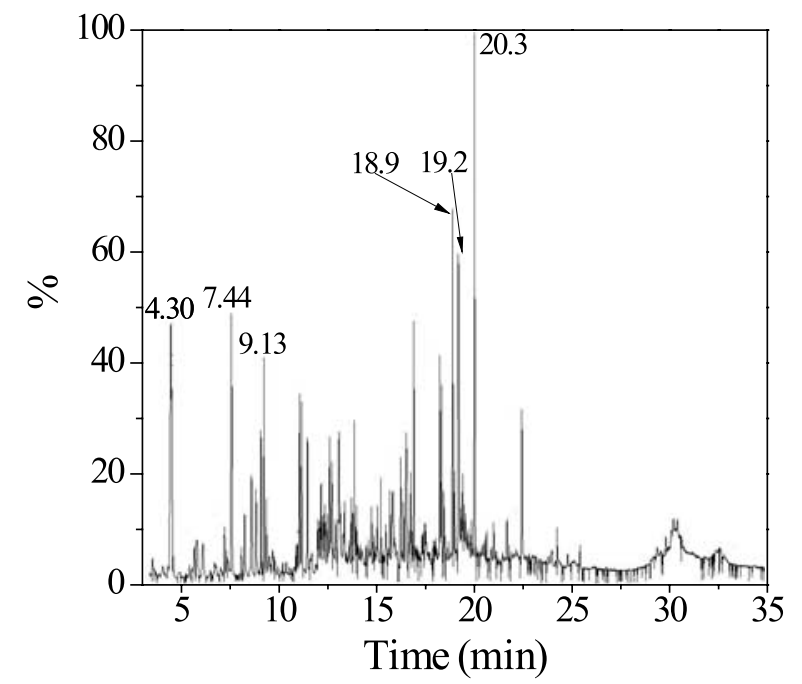

Fig. 6 GC-MS chromatogram of bio-oil from cellulose.

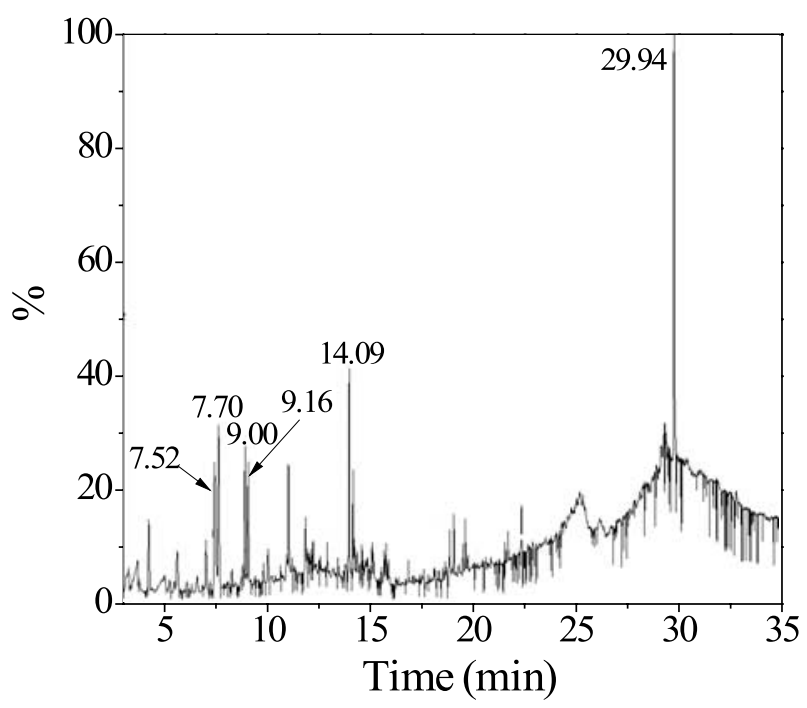

Fig. 7 GC-MS chromatogram of bio-oil from rice stalk.

esters. The contents of main organic compounds in biooils obtained with different kinds of molten salts were similar. There were some differences on component among bio-oils obtained from different biomass. 


\section{Conclusion}

In this study, a new way to obtain bio-oil from biomass, pyrolysis biomass in molten salts, was proposed and investigated. The experimental results showed the feasibility of this method and the main characteristics of this method are as follows: (1) Biomass particles can be heated to scheduled reaction temperature while they meet with molten salt quickly and homogeneously. Because the heat capacity of molten salt is much higher than the biomass material, the temperature of molten salt can be kept only slightly higher than pyrolysis reaction temperature. Demands on quality of heat source, heat tolerance of equipments and thermal insulation performance could be reduced a lot. (2) During the process of biomass pyrolysis, molten salt can be simultaneously used as heat carrier, catalyst and solvent. Therefore, biomass pyrolysis in molten salt may be recognized as a potential technology based on both advantages of fast pyrolysis and high pressure liquefaction.

Two biomass materials and six kinds of molten salts were investigated from the view of the effects of pyrolysis parameters and composition of molten salts on product yields and compound compositions of the bio-oil. Product yields and compound compositions of bio-oil products can be adjusted by varying compositions of molten salts. The bio-oil from pyrolysis of biomass in molten salts is a complicated organic compound. The furan derivatives were absolutely dominant in content. Bio-oil from cellulose contained notable content of glucose esters. Product yield of the bio-oil from cellulose was higher than that from rice stalk. On contrast, water content of the bio-oil from cellulose was lower than that form rice stalk. It was concluded that biomass with higher content of cellulose is appropriate feed for pyrolysis in molten salts. The pyrolysis greatly depended on temperature and the yield of bio-oil increased at first and then decreased with the increasing of temperature. The optimal temperature of cellulose pyrolysis is about $530^{\circ} \mathrm{C}$.

\section{Acknowledgement}

The authors gratefully acknowledge the financial sup- port from the National Natural Science Foundation of China (20876150) and the Scientific Research Foundation of Zhejiang University of Technology (0901101003408 and 101007529).

\section{References}

1) H. F. Gercel, Bioresour. Technol., 85, 113 (2002).

2) S. Sensoz, D. Angin, and S. Yorgun, Biomass Bioenergy, 19, 271 (2000).

3) A. E. Putun, Energy Sources B, 24, 275 (2002).

4) C. Acikgoz, O. Onay, and O. M. Kockar, J. Anal. Appl. Pyrolysis, 71, 417 (2004).

5) M. Xiaoling, W. Qingyu, and Y. Changyan, J. Anal. Appl. Pyrolysis, 71, 855 (2004).

6) L. Zhongyang, W. Shurong, and L. Yanfen, Biomass Bioenergy, 26, 455 (2004).

7) B. Xueyuan, Y. Weiming, and W. Lihong, Transactions Chin. Soc. Agric. Eng., 127 (2005).

8) A. Debdoubi, A. Elamarti, and E. Colacio, Int. J. Energy Res., 30, 1243 (2006).

9) L. Ronghou and L. Jingde, Transactions Chin. Soc. Agric. Eng., 187 (2008).

10) S. Sensoz and D. Angin, Bioresour. Technol., 99, 5498 (2008).

11) Y. -H. Park, J. Kim, S. -S. Kim, and Y. -K. Park, Bioresour. Technol., 100, 400 (2009).

12) E. Sada, H. Kumazawa, and M. Kudsyt, Ind. Eng. Chem. Res., 31, 612 (1992).

13) M. Kudsy and H. Kumazawa, Can. J. Chem. Eng., 77, 1176 (1999).

14) R. Fahmi, A. V. Bridgwater, I. Donnison, N. Yates, and J. M. Jones, Fuel, 87, 1230 (2008).

15) N. Shimada, H. Kawamoto, and S. Saka, J. Anal. Appl. Pyrolysis, 81, 80 (2008).

16) A. Willams and A. Patrick, Renewable Energy, 4, 1 (1994).

17) G. N. Richards and G. C. Zheng, J. Anal. Appl. Pyrolysis, 21, 133 (1991).

18) F. Suarez, A. Martinez, and J. M. D. Tascon, J. Anal. Appl. Pyrolysis, 62, 93 (2002).

19) Q. Lu, W. -M. Xiong, W. -Z. Li, Q. -X. Guo, and X. -F. Zhu, Bioresour. Technol., 100, 4871 (2009).

20) M. M. Ibrahim and M. S. Seehra, Energy Fuels, 5, 74 (1991). 